August - 2021

\title{
Is the Understanding Dementia Massive Open Online Course Accessible and Effective for Everyone? Native Versus Non-Native English Speakers
}

Sarang Kim*, Aidan Bindoff, Maree Farrow, Fran McInerney, Jay Borchard, and Kathleen Doherty

Wicking Dementia Research \& Education Centre, College of Health and Medicine, University of Tasmania, Australia

${ }^{*}$ Corresponding author

\begin{abstract}
Most massive open online courses (MOOCs) are offered in English, including those offered by nonEnglish speaking universities. The study investigated an identified English language dementia MOOC's accessibility and effectiveness in improving the dementia knowledge of non-native English speaker participants. A total of 6,389 enrolees (age range 18-82 years; $88.4 \%$ female) from 67 countries was included in analyses. Dementia knowledge was measured by the Dementia Knowledge Assessment Scale (DKAS) before and after the MOOC completion. Rates of completion were also compared. Native English speakers ( $n=5,320$ ) were older, more likely to be female, less likely to be employed, and had lower educational attainment than non-native English speakers $(n=1025)$. Native English speakers were also more likely to care for or have cared for a family member or friend living with dementia than were non-native English speakers. Native English speakers had a significantly higher DKAS score both pre- $(M=33.0, S D=9.3)$ and post-MOOC $(M=44.2, S D=5.5)$ than did non-native English speakers ( $M=31.7, S D=9.1$; and $M=40.7, S D=7.7$ for pre- and post-MOOC, respectively). Non-native English speakers with low pre-MOOC dementia knowledge scores gained significantly less dementia knowledge following course completion than did native English speakers ( $p<$.oo1, adjusted for age and education). There was no significant difference between the two groups in their likelihood of completing the MOOC. Our findings suggest that non-native English speakers are motivated and able to complete the MOOC at similar rates to native English speakers, but the MOOC is a more effective educational intervention for native English speakers with low dementia knowledge.
\end{abstract}

Keywords: massive open online course, dementia, effectiveness, accessible, non-English speakers, MOOC 


\section{Introduction}

Globally, approximately 50 million people have dementia, with this number expected to almost triple by 2050 (Alzheimer's Disease International, 2019). Many more people's lives are affected by the condition physically, psychologically, and economically, as dementia not only affects those people living with dementia but their family members, friends, and the professionals working with them as well.

However, in most countries there is a lack of awareness and understanding of dementia, resulting in negative attitudes or stigmatisation of people living with dementia, and barriers to diagnosis and care (World Health Organization, 2015). Some studies have shown that the general public demonstrates a reasonably good level of awareness and knowledge about dementia (McParland et al., 2012) or common dementia symptoms (Cahill et al., 2015; Loi \& Lautenschlager, 2015). However, the public has expressed uncertainty about less known or early symptoms, treatments, risk factors, and care (Breining et al., 2014; Ludecke et al., 2016; McParland et al., 2012; Roberts et al., 2014; Robinson et al., 2014). There is thus a need to educate people about wider aspects of dementia to improve outcomes for prevention, diagnosis, and care.

Dementia can be experienced and constructed in diverse ways (Faure-Delage et al., 2012). For instance, some cultures consider dementia as a normal part of ageing, while others perceive dementia as a mental illness, or linked to supernatural or spiritual beliefs (Batsch \& Mittelman, 2012). Ethnic or cultural differences have also been found in dementia knowledge and perspectives. Ethnic minority groups in predominantly white/Caucasian English speaking countries are reported to both lack knowledge about dementia (Ayalon, 2013; Ayalon \& Arean, 2004; Connell et al., 2007; Low et al., 2010), and hold more negative attitudes or stigma toward people living with dementia (Lee et al., 2010; Low et al., 2010). This is especially so for those less acculturated and/or who do not speak English. An Australian national survey found that those who spoke a language other than English had a lower level of knowledge regarding dementia risk reduction behaviours than did English speaking respondents (Smith et al., 2014). One-third of Australians have come from culturally and linguistically diverse backgrounds (Australian Institute of Health and Welfare, 2016); this is of particular interest in that country. Even so, other more global factors such as the projected rate of increase in dementia being greatest in regions such as Africa and Asia (Prince et al., 2015) serve as additional imperatives to explore ways to meet the dementia information needs of those from non-English speaking backgrounds.

Massive open online courses (MOOCs) are a scalable and accessible mode of education as they can offer world-class teaching and educational resources beyond geographical and social boundaries (Hone \& El Said, 2016). Anyone can access MOOCs, in many cases free of cost, provided they have Internet access, along with sufficient computer and language proficiency (Liyanagunawardena \& Williams, 2014). The potential benefits may be equalising for those people in developing countries, where attending classes at top universities face-to-face is often not possible. MOOCs have the potential to democratise education and transform the higher educational landscape (Rambe \& Moeti, 2017).

Most MOOCs are offered in English (Liyanagunawardena \& Williams, 2014), even those offered by nonEnglish speaking universities (Altbach, 2014). MOOCs on dementia are no exception. There are a total of 19 dementia-related MOOCs in English and one in Spanish (Class Central, 2020). This situation may exclude many potential learners who do not speak either language (Altbach, 2014). MOOCs have been criticised both for their low completion rates and being mainly for so-called privileged people from the world's most affluent countries who already have access to digital technologies, international 
language learning opportunities, and information about MOOCs (Kizilcec et al., 2017; Liyanagunawardena et al., 2013). Furthermore, as the optimal language for learning is believed to be the learner's native tongue (United Nations Education, Scientific and Cultural Organization [UNESCO], 2008), the effectiveness of MOOCs may vary depending on the language in which the course is offered. However, little is known about the likelihood of non-native English speakers completing such courses and the accessibility of these courses. We know little about whether people with different language backgrounds are able to perceive, understand, navigate, and interact with a MOOC (Web Accessibility Initiative, 2019). The current study therefore investigated how accessible and effective an identified dementia MOOC was for non-native English speakers (i.e., English is not their first language) compared to native English speakers for whom English is their first language.

\section{Materials and Methods}

\section{Participants and Procedures}

In 2017, 29,025 people from around the world enrolled in the Understanding Dementia MOOC (UDMOOC). The UDMOOC, developed in 2013 by the Wicking Dementia Research and Education Centre at the University of Tasmania, is a highly ranked (Class Central, 2019) nine-week online course that provides content about dementia pathology, symptoms, risk factors, medical management, progression, and care across three modules (King et al., 2014). For this study, 15,783 enrolees consented for their data to be used for research purposes. Consenting enrolees were excluded from all analyses if they did not complete both the sign-up survey and Dementia Knowledge Assessment Scale (DKAS) questionnaire before completing the first UDMOOC module, leaving a sample of 6,389 participants from 67 countries.

The course was offered to anyone who wished to enrol. Participants received reminder and notification e-mails about new modules being released and the closing date for the course as it progressed. Participation in this research was voluntary. This project received ethical approval from the University of Tasmania's Human Research Ethics Committee.

\section{Data Collection}

This study collected four main sets of data. Sociodemographic information was collected, including (a) age; (b) gender; (c) country of residence; (d) employment status (i.e., currently working vs. currently not working); (e) education level (i.e., high school and below, pre-tertiary, undergraduate university degree, postgraduate degree, and other); and (f) English language background (i.e., native vs. nonnative). Participants' relationships with people living with dementia were also examined. Data was collected about whether they (a) were a person living with dementia themselves, (b) had a family member living with dementia, (c) had a friend living with dementia, (d) had ever provided care for someone living with dementia, and (e) had ever worked professionally with people living with dementia.

Dementia knowledge was measured using the DKAS (Annear et al., 2017), a 25-item English-language validated scale with five response options per item: false, probably false, probably true, true, and don't know. The DKAS comprises statements about dementia that are both factually correct (e.g., Alzheimer's disease is the most common form of dementia) and incorrect (e.g., dementia is a normal part of the ageing process). Participants received two points for a correct true or false response, one point for a 
correct probably true or probably false response, and zero points for an incorrect or don't know response. Total scores ranged from o to 50 . Completion of the course was recorded by obtaining a score of $70 \%$ or higher on end-of-module quizzes for all three MOOC modules.

\section{Analysis}

Demographic characteristics for native and non-native English speakers were compared with independent samples $t$ tests for continuous variables and chi-square tests for categorical variables. Logistic regression was used to examine the association of demographic characteristics and baseline dementia knowledge with the completion of the course. A penalised regression spline was fitted for age, as the association between age and expected probability of completion was not linear. Linear multiple regression was used to examine the association between post-UDMOOC DKAS scores and demographic variables, adjusted for baseline DKAS scores. A penalised regression spline was fitted for age, as again the association between age and post-UDMOOC DKAS scores was not linear. Interaction models were fitted to assess differential rates of completion and post-UDMOOC dementia knowledge gain among non-native and native English speakers at different levels of educational attainment and baseline DKAS scores. Analyses were conducted in R version 3.6 and in STATA version 15.

\section{Results}

Table 1 shows descriptive characteristics for native English speakers $(n=5320)$, and non-native English speakers $(n=1025)$. Native English speakers were older, more likely to be female, less likely to be employed, and had lower educational attainment than did non-native English speakers. Native English speakers were also more likely to care for or have cared for a family member or friend living with dementia (26\%) than were non-native English speakers (21\%). In addition, most non-native English speakers reported living in either Australia (61\%) or another English-speaking country (28\%). 
Table 1

Sample Characteristics of the UDMOOC Enrolees: Comparing Native and Non-Native English Speakers

\begin{tabular}{|c|c|c|c|c|}
\hline & & Number (perce & & Statistics; $p$ value \\
\hline Characteristic & Total $(N=6,389)$ & $\begin{array}{l}\text { Native English speaker } \\
(n=5,320)\end{array}$ & $\begin{array}{l}\text { Non-Native English speaker } \\
(n=1,025)\end{array}$ & \\
\hline Age group & & & & $\chi(3)=435.69 ; p<0.001$ \\
\hline 30 years and younger & $1,650(25.8)$ & $1,122(21.1)$ & $514(50.1)$ & \\
\hline 31 to 40 years & $1,796(28.1)$ & $1,495(28.1)$ & $285(27.8)$ & \\
\hline 41 to 50 years & $1,941(30.4)$ & $1,787(33.6)$ & $144(14.0)$ & \\
\hline Older than 50 years & $1,002(15.7)$ & $918(17.2)$ & $82(8.0)$ & \\
\hline Gender & & & & $\chi(1)=47.55 ; p<0.001$ \\
\hline Male & $733(11.6)$ & $549(10.4)$ & $183(17.9)$ & \\
\hline Female & $5,606(88.4)$ & $4,742(89.6)$ & $838(82.1)$ & \\
\hline Country of residence & & & & $\chi(2)=422.38 ; p<0.001$ \\
\hline Non-English-speaking country & $153(2.4)$ & $37(0.7)$ & $115(11.2)$ & \\
\hline Australia & $4,622(72.3)$ & $3,966(74.5)$ & $625(61.0)$ & \\
\hline Other English-speaking country & $1,614(25.3)$ & $1,317(24.8)$ & $285(27.8)$ & \\
\hline Employed & $5,021(79.0)$ & $4,161(78.5)$ & $838(82.1)$ & $\chi(1)=6.80 ; p<0.01$ \\
\hline Education & & & & $\chi(4)=188.29 ; p<0.001$ \\
\hline High school and below & $710(11.4)$ & $664(12.8)$ & $43(4.3)$ & \\
\hline Pre-Tertiary & $2,491(39.9)$ & $2,173(41.8)$ & $294(29.2)$ & \\
\hline Bachelor's degree & $1,516(24 \cdot 3)$ & $1,129(21.7)$ & $379(37.6)$ & \\
\hline Postgraduate & $1,438(23.0)$ & $1,151(22.1)$ & $280(27.8)$ & \\
\hline Other & $94(1.5)$ & $82(1.6)$ & $11(1.1)$ & \\
\hline Person with dementia & $29(0.5)$ & $28(0.5)$ & $1(0.1)$ & $\chi(3)=11.41 ; p<0.05$ \\
\hline Family with dementia & $3,446(54.7)$ & $3,038(57.9)$ & $382(37.8)$ & $\chi(1)=137.79 ; p<0.001$ \\
\hline Friend with dementia & $3,309(52.4)$ & $2,835(53.9)$ & $450(44 \cdot 3)$ & $\chi(1)=30.99 ; p<0.001$ \\
\hline Provided care & $1,612(25.4)$ & $1,383(26.2)$ & $216(21.3)$ & $\chi(1)=10.95 ; p<0.005$ \\
\hline Work with people with dementia & $4,366(68.9)$ & $3,630(68.8)$ & $711(69.6)$ & $\chi(1)=0.30 ; p=.586$ \\
\hline Pre-DKAS score $(M, S D)$ & $32.78(9.29)$ & $33.01(9.33)$ & $31.65(9.07)$ & $t(6,343)=-4.28 ; p<0.001$ \\
\hline Post-DKAS score $(M, S D)$ & $43.62(6.02)$ & $44.18(5.47)$ & $40.70(7.71)$ & $t(1,948)=-9.59 ; p<0.001$ \\
\hline
\end{tabular}

Note. Regarding discrepancy in total number compared to number of native versus non-native English speakers, 44 participants did not respond as to whether or not English was their first language. 


\section{Completion Rate}

There was no significant difference between the two language groups in terms of their likelihood of completing the UDMOOC, $(O R=.97$ [95\% CI: .84, 1.12]; $p=.694)$, with an unadjusted completion rate of $65.5 \%$ and $65.4 \%$ for native and non-native English speakers, respectively. Females, Australian residents, and people with higher baseline dementia knowledge scores were significantly more likely to complete the UDMOOC. Educational attainment was significantly associated with course completion; rates of completion increased with levels of educational attainment (Table 2). However, there were no significant interactions between non-native English speaking and education $\left(\chi^{2}{ }_{3}=6.6, p=.084\right)$ or baseline DKAS scores $\left(\chi^{2}{ }_{1}=.4, p=.509\right)$, as illustrated in Figure 1a. 
Is the Understanding Dementia Massive Open Online Course Accessible and Effective for Everyone?

Kim, Bindoff, Farrow, McInerney, Borchard, and Doherty

Table 2

Odds Ratios with 95\% Confidence Intervals for Expected UDMOOC Completion

\begin{tabular}{|c|c|c|c|c|c|c|c|c|c|c|c|c|c|c|c|}
\hline \multirow[b]{2}{*}{ Predictor } & \multicolumn{15}{|c|}{ UDMOOC Completion } \\
\hline & $\begin{array}{l}\text { Odds } \\
\text { ratio }\end{array}$ & $\mathrm{CI}$ & $p$ & $\begin{array}{l}\text { Odds } \\
\text { ratio }\end{array}$ & CI & $p$ & $\begin{array}{l}\text { Odds } \\
\text { ratio }\end{array}$ & CI & $p$ & $\begin{array}{l}\text { Odds } \\
\text { ratio }\end{array}$ & CI & $p$ & $\begin{array}{l}\text { Odds } \\
\text { ratio }\end{array}$ & CI & $p$ \\
\hline (Intercept) & 1.9 & $1.79-2.01$ & $<0.001$ & 1.92 & $1.80-2.06$ & $<0.001$ & 1.28 & $1.10-1.48$ & 0.002 & 0.92 & $0.75-1.14$ & 0.464 & 1.1 & $0.78-1.56$ & 0.58 \\
\hline $\begin{array}{l}\text { English (non- } \\
\text { native) }\end{array}$ & 0.97 & $0.84-1.12$ & 0.694 & 1.13 & $0.98-1.32$ & 0.101 & 1.06 & $0.91-1.23$ & 0.448 & 1.4 & $0.83-2.34$ & 0.205 & & & \\
\hline Carer & & & & 0.9 & $0.79-1.01$ & 0.082 & & & & & & & & & \\
\hline $\begin{array}{l}\text { Age (penalised } \\
\text { spline) }\end{array}$ & & & & 135.9 & & $<0.001$ & $157 \cdot 3$ & & $<0.001$ & 142.8 & & $<0.001$ & & & \\
\hline $\begin{array}{l}\text { Education: Pre- } \\
\text { tertiary }\end{array}$ & & & & & & & 1.39 & $1.17-1.65$ & $<0.001$ & & & & & & \\
\hline $\begin{array}{l}\text { Education: } \\
\text { University }\end{array}$ & & & & & & & 1.71 & $1.42-2.07$ & $<0.001$ & & & & & & \\
\hline $\begin{array}{l}\text { Education: } \\
\text { Honours and } \\
\text { postgrad }\end{array}$ & & & & & & & 1.76 & $1.45-2.12$ & $<0.001$ & & & & & & \\
\hline $\begin{array}{l}\text { DKAS score } \\
\text { (pre- } \\
\text { UDMOOC) }\end{array}$ & & & & & & & & & & 1.02 & $1.02-1.03$ & $<\mathbf{0 . 0 0 1}$ & & & \\
\hline $\begin{array}{l}\text { Non-native } \\
\text { English x } \\
\text { DKAS score } \\
\text { (pre- } \\
\text { UDMOOC) }\end{array}$ & & & & & & & & & & 0.99 & $0.98-1.01$ & 0.471 & & & \\
\hline Female & & & & & & & & & & & & & 1.23 & $1.05-1.45$ & 0.012 \\
\hline $\begin{array}{l}\text { Australian } \\
\quad \text { resident }\end{array}$ & & & & & & & & & & & & & 1.53 & $1.10-2.12$ & 0.011 \\
\hline $\begin{array}{l}\text { Resident of } \\
\text { other English- } \\
\text { speaking } \\
\text { country }\end{array}$ & & & & & & & & & & & & & 1.23 & $0.87-1.72$ & 0.232 \\
\hline Observations & & & 6,113 & & & 6,068 & & & 6,113 & & & 6,113 & & & 6,108 \\
\hline $\begin{array}{l}\text { Akaike } \\
\text { information } \\
\text { criterion }\end{array}$ & & & $7,888.7$ & & & $7,762.8$ & & & $7,789.0$ & & & $7,779 \cdot 3$ & & & $7,861.1$ \\
\hline
\end{tabular}




\section{Figure 1}

UDMOOC Completion and Dementia Knowledge Scores
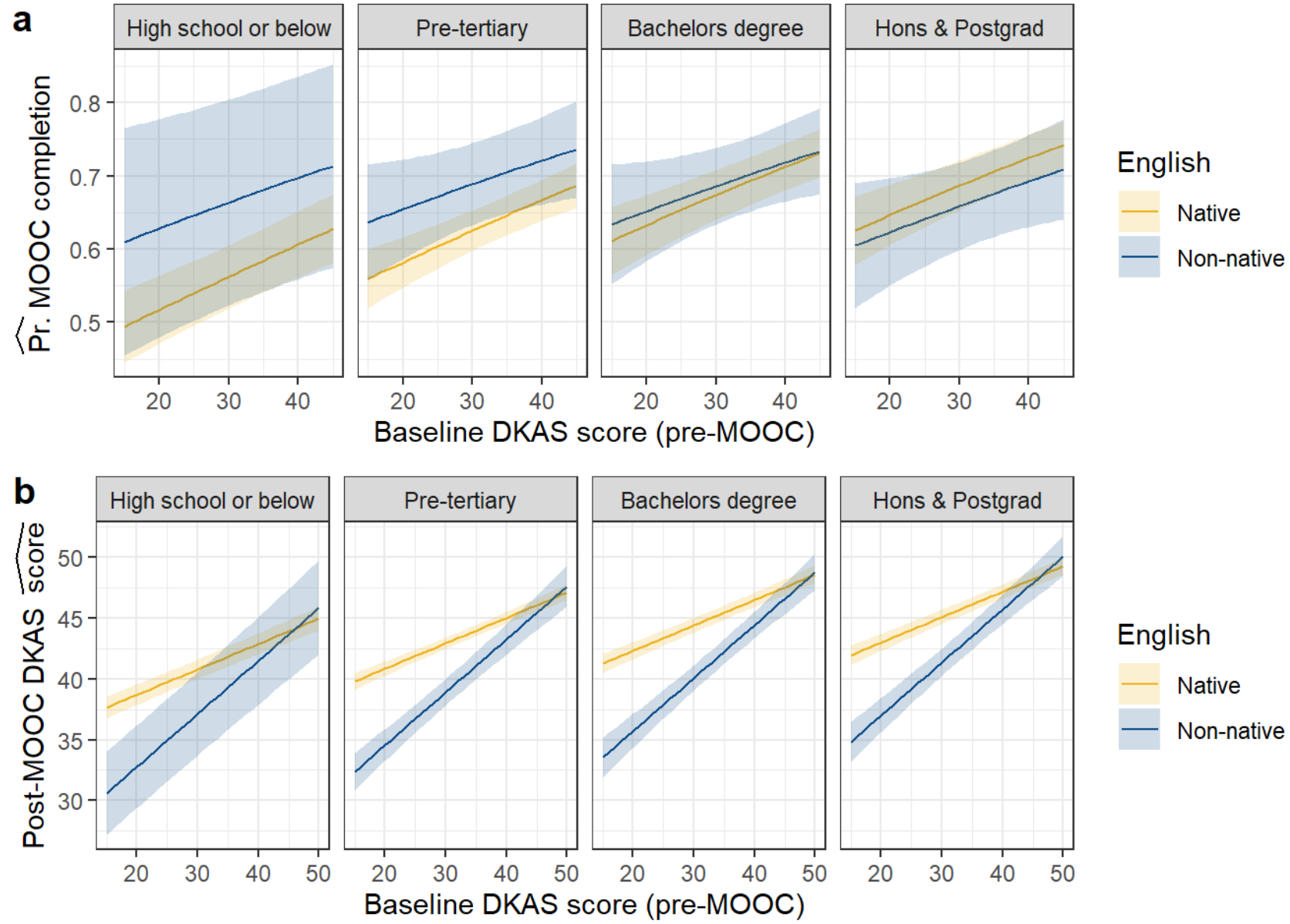

English

Native

Non-native

Note. Estimated proportion of UDMOOC completion ( a) and post-UDMOOC dementia knowledge score (b) at different levels of educational attainment and baseline dementia knowledge (shown on $\mathrm{x}$ axes). Age held at mean for the cohort (39 years).

\section{Dementia Knowledge}

Native English speakers had significantly higher DKAS scores both pre- $(M=33.0, S D=9.3 ; t(6343)=$ -4.3; $p<0.001)$ and post-UDMOOC $\left(M=44.2, S D=5.5 ; \mathrm{t}_{(1948)}=-9.6 ; p<0.001\right)$ than did non-native English speakers ( $M=31.7, S D=9.1$ and $M=40.7, S D=7.7$ for pre- and post-UDMOOC, respectively). Adjusted for baseline DKAS score and age, non-native English speakers obtained lower post-UDMOOC DKAS scores by an average of 3.1 points ([95\% CI: 2.4, 3.7], $p<.001$ ). Education was significantly positively associated with post-UDMOOC DKAS scores (Table 3), however caring for a person with dementia was not. In contrast to results for completion rates, there was a significant interaction between non-native English speaking and baseline DKAS scores $\left(\chi^{2}{ }_{1}=36.3, p<.001\right)$; native English speakers with low baseline DKAS scores obtained significantly greater increases in DKAS scores following UDMOOC completion (illustrated in Figure 1b). This result was consistent after adjusting for education and for caring for a person with dementia. The observed difference in slopes was .22 points (95\% CI: .15, .30) per baseline DKAS point. 
Table 3

Unstandardized Regression Coefficients with 95\% Confidence Intervals for Post-UDMOOC Dementia Knowledge Scores

\begin{tabular}{|c|c|c|c|c|c|c|c|c|c|c|c|c|}
\hline \multirow[b]{2}{*}{ Predictor } & \multicolumn{12}{|c|}{ Post-UDMOOC DKAS score } \\
\hline & $\beta$ & CI & $p$ & $\beta$ & $\mathrm{CI}$ & $p$ & $\beta$ & $\mathrm{CI}$ & $p$ & $\beta$ & $\mathrm{CI}$ & $p$ \\
\hline (Intercept) & 35.28 & $34.36-36.20$ & $<0.001$ & 34.4 & $33.29-35.51$ & $<0.001$ & 36.41 & $35.43-37.39$ & $<0.001$ & 33.77 & $31.65-35.88$ & $<0.001$ \\
\hline $\begin{array}{l}\text { DKAS score (pre- } \\
\text { UDMOOC) }\end{array}$ & 0.27 & $0.24-0.29$ & $<\mathbf{0 . 0 0 1}$ & 0.21 & $0.18-0.24$ & $<\mathbf{0 . 0 0 1}$ & 0.23 & $0.21-0.26$ & $<0.001$ & 0.26 & $0.24-0.29$ & $<0.001$ \\
\hline English (non-native) & -3.07 & $-3.74--2.40$ & $<0.001$ & -10.7 & $-13.17--8.31$ & $<\mathbf{0 . 0 0 1}$ & -10.3 & $-12.80--7.78$ & $<0.001$ & -2.95 & $-3.64--2.26$ & $<0.001$ \\
\hline Age (penalised spline) & 1 & & 0.026 & 2.8 & & 0.002 & 1 & & 0.02 & 1 & & $\mathbf{0 . 0 3 4}$ \\
\hline Education: Pre-tertiary & & & & 2.13 & $1.28-2.97$ & $<\mathbf{0 . 0 0 1}$ & & & & & & \\
\hline Education: University & & & & 3.53 & $2.63-4.43$ & $<0.001$ & & & & & & \\
\hline $\begin{array}{l}\text { Education: Honours and } \\
\text { postgrad }\end{array}$ & & & & $4 \cdot 34$ & $3.45-5.23$ & $<\mathbf{0 . 0 0 1}$ & & & & & & \\
\hline $\begin{array}{l}\text { Non-native English x } \\
\text { DKAS score (pre- } \\
\text { UDMOOC) }\end{array}$ & & & & 0.22 & $0.15-0.30$ & $<0.001$ & 0.22 & $0.15-0.29$ & $<0.001$ & & & \\
\hline Carer & & & & & & & -0.31 & $-0.88-0.27$ & 0.294 & & & \\
\hline Australian resident & & & & & & & & & & 1.73 & $-0.06-3.53$ & 0.059 \\
\hline $\begin{array}{l}\text { Resident of other } \\
\text { English-speaking } \\
\text { country }\end{array}$ & & & & & & & & & & 1.36 & $-0.48-3.20$ & 0.147 \\
\hline Female & & & & & & & & & & 0.02 & $-0.77-0.81$ & 0.962 \\
\hline Observations & & & 1,891 & & & 1,891 & & & 1,883 & & & 1,879 \\
\hline $\begin{array}{l}\text { Akaike information } \\
\text { criterion }\end{array}$ & & & $11,720.5$ & & & $11,585 \cdot 3$ & & & $11,640.9$ & & & $11,641.6$ \\
\hline
\end{tabular}




\section{Discussion}

This study explored how accessible and effective the UDMOOC is in providing dementia education for non-native English speakers compared to native English speakers. The results indicated that the UDMOOC was accessible to people around the world who were able to perceive, understand, navigate, and complete course modules. However, the characteristics of the UDMOOC enrolees who were native and non-native English speakers were significantly different. The UDMOOC attracted non-native English speakers who were relatively young, highly educated, employed, living in an English-speaking country, and who had fewer personal relationships with people living with dementia. This suggested that the UDMOOC may not have reached more disadvantaged non-native English speaking learners who would not ordinarily have access to educational opportunities (Emanuel, 2013). Instead, we recruited a profile of non-native English speakers similar to the profile reported as typical of Englishspeaking participants in other MOOCs (Kizilcec et al., 2017; Liyanagunawardena et al., 2013). While providing education online may maximise reach, its participants are inevitably those with Internet access.

The completion rate for the UDMOOC we studied was much higher than in other studies (Goldberg et al., 2015; Jordan, 2014) due to including only those who completed the DKAS. However, our findings that completion rates did not differ between native and non-native English speakers demonstrated that the UDMOOC module content was accessible to non-native English speakers. This is in line with another dementia MOOC with a higher completion rate than MOOCs addressing different subject matter, such as digital literacy (Hadi \& Rawson, 2016). This suggests that dementia is a topic of interest for many people around the world, and that those interested in learning about dementia may be, for various reasons, more motivated or likely to complete the course than those who sign up for MOOCs on other areas topics.

Although the UDMOOC was accessible to anyone who understands English, the findings from this study of a greater increase in dementia knowledge for native English speakers suggests that it was a more effective tool for this cohort. This was despite non-native English speakers having higher educational attainment than native English speakers, while education attainment associated with increased postUDMOOC knowledge scores and greater likelihood of course completion. Caring experience, however, did not have a significant effect on improvement of post-UDMOOC DKAS scores when native and nonnative English speakers were compared. This is in line with previous research where education through the UDMOOC was significantly associated with post-UDMOOC DKAS scores regardless of previous experience of dementia (Eccleston et al., 2019).

Our findings support the claim that the optimal language for learning is the learner's native language (UNESCO, 2008). This supports the case for translation and culturally appropriate adaptation (Altbach, 2014) of this course, both to enhance learners' understanding as well as reach additional communities and learners needing dementia education. Our results suggest that this will be especially important for attracting and effectively educating non-English speakers who have lower educational attainment, such as the many older care workers currently working in Australia (Mavromaras et al., 2017) and overseas (Hart \& Mareno, 2014; Small et al., 2015; Walsh \& Shutes, 2013). Such modifications might serve to improve understanding of dementia and the care provided to people living with dementia. 


\section{Limitations}

First, proficiency in English was not measured. It was assumed that those who reported English was not their first language would be less proficient in English. Future studies should therefore seek information on participants' level of English proficiency in order to examine the role this might play when learning through English language MOOCs. In addition, to explore whether the lower post-UDMOOC DKAS scores in non-native English speakers found in this study were due to language barriers, a randomised controlled trial should be conducted wherein non-native English speakers are randomly assigned to either the course in English or in their native language. A second possible limitation was that data came from those enrolees who consented to the research, and who completed both the initial (mandatory) survey and the DKAS questionnaire (optional). As a result, these enrolees might have been more interested or motivated to complete the course than those who did not complete the optional DKAS questionnaire. This may partly explain the high completion rate (65.4\%) found in this study compared to previously reported overall $38 \%$ completion rate for the UDMOOC (Goldberg et al., 2015), which includes those who enrolled but did not progress to this point in the course.

\section{Conclusion}

Despite the limitations above, this study contributes towards current literature on the strengths and weaknesses of MOOCs, and the potential benefits of conducting dementia education through a MOOC platform. The UDMOOC encouraged learners to learn autonomously with the support of the massive number of other learners in the course, as well as interaction with lecturers, which might contribute to the UDMOOC's high learner satisfaction rates (Doherty et al., 2018). The UDMOOC, however, was likely unable to reach many non-English speakers who need dementia education, due to language barriers or inability to access the Internet or MOOCs. Future iterations of this MOOC therefore should consider being available in multiple languages with appropriately and culturally adapted content, with active promotion in non-English speaking countries to help more people know about and gain access to greatly needed dementia education.

\section{Acknowledgements}

This work was supported by the J. O. \& J. R. Wicking Trust. 


\section{References}

Altbach, P., G. (2014). MOOCs as neocolonialism: Who controls knowledge? International Higher Education, 75, 5-7. https://doi.org/10.6017/ihe.2014.75.5426

Alzheimer's Disease International. (2019). World Alzheimer report 2019: Attitudes to dementia. https://www.alzint.org/u/WorldAlzheimerReport2019.pdf

Annear, M. J., Toye, C., Elliott, K.-E. J., McInerney, F., Eccleston, C., \& Robinson, A. (2017). Dementia knowledge assessment scale (DKAS): Confirmatory factor analysis and comparative subscale scores among an international cohort. BMC Geriatrics, 17(1), 168. https://doi.org/10.1186/s12877-017-0552-y

Australian Institute of Health and Welfare. (2016). Exploring the aged care use of older people from culturally and linguistically diverse backgrounds: A feasibility study. https://www.aihw.gov.au/getmedia/55509a73-450d-42e4-9841b7ed6f58c3ee/20342.pdf.aspx?inline=true

Ayalon, L. (2013). Re-examining ethnic differences in concerns, knowledge, and beliefs about Alzheimer's disease: Results from a national sample. International Journal of Geriatric Psychiatry, 28(12), 1288-1295. https://doi.org/10.1002/gps.3959

Ayalon, L., \& Arean, P. A. (2004). Knowledge of Alzheimer's disease in four ethnic groups of older adults. International Journal of Geriatric Psychiatry, 19(1), 51-57. https://doi.org/10.1002/gps.1037

Batsch, N. L., \& Mittelman, M. S. (2012). World Alzheimer report 2012: Overcoming the stigma of dementia. https://www.alzint.org/u/WorldAlzheimerReport2012.pdf

Breining, A., Lavallart, B., Pin, S., Leon, C., Moulias, S., Arwidson, P., Beck, F., Berr, C., \& Verny, M. (2014). Perception of Alzheimer's disease in the French population. Journal of Nutrition, Health and Aging, 18(4), 393-399. https://doi.org/10.1007/s12603-014-0008-4

Cahill, S., Pierce, M., Werner, P., Darley, A., \& Bobersky, A. (2015). A systematic review of the public's knowledge and understanding of Alzheimer's disease and dementia. Alzheimer Disease and Associated Disorders, 29(3), 255-275. https://doi.org/10.1097/wad.0000000000000102

Class Central. (2019). Top 100 free online courses. https://www.classcentral.com/collection/top-freeonline-courses

Class Central. (2020). https://www.classcentral.com/search?q=dementia

Connell, C. M., Scott Roberts, J., \& McLaughlin, S. J. (2007). Public opinion about Alzheimer disease among Blacks, Hispanics, and Whites: Results from a national survey. Alzheimer Disease and Associated Disorders, 21(3), 232-240. https://doi.org/10.1097/WAD.obo13e3181461740

Doherty, K., Bindoff, A., Robinson, A., Vickers, J., \& McInerney, F. (2018). Sustainability of the understanding dementia MOOC: Participant motivation and engagement [Poster 
presentation]. 33rd International Conference of Alzheimer's Disease International, Chicago, USA.

Eccleston, C., Doherty, K., Bindoff, A., Robinson, A., Vickers, J., \& McInerney, F. (2019). Building dementia knowledge globally through the Understanding Dementia massive open online course (MOOC). Science of Learning, 4(1), 3. https://doi.org/10.1038/s41539-019-0042-4

Emanuel, E. J. (2013). MOOCs taken by educated few. Nature, 503, 342. https://doi.org/10.1038/503342a

Faure-Delage, A., Mouanga, A. M., M’Belesso, P., Tabo, A., Bandzouzi, B., Dubreuil, C.-M., Preux, P.M., Clément, J.-P., \& Nubukpo, P. (2012). Socio-Cultural perceptions and representations of dementia in Brazzaville, Republic of Congo: The EDAC survey. Dementia and Geriatric Cognitive Disorders Extra, 2(1), 84-96. https://doi.org/10.1159/000335626

Goldberg, L. R., Bell, E., King, C., O’Mara, C., McInerney, F., Robinson, A., \& Vickers, J. (2015). Relationship between participants' level of education and engagement in their completion of the Understanding Dementia massive open online course. BMC Medical Educucation, 15, 60. https://doi.org/10.1186/s12909-015-0344-Z

Hadi, S. M., \& Rawson, R. (2016, February 22-24). Driving learner engagement and completion within MOOCs: A case for structured learning support. In M. Khalil, M. Ebner, M. Kopp, A. Lorenz \& M. Kalz (Eds.), Proceedings of the European stakeholder summit on experiences and best practices in and around MOOCs (EMOOCS 2016, pp. 81-92), Graz, Austria. https://www.researchgate.net/publication/293884848 Proceedings of the European Sta keholder Summit on experiences and best practices in and around MOOCs EMOOC S 2016

Hart, P. L., \& Mareno, N. (2014). Cultural challenges and barriers through the voices of nurses. Journal of Clinical Nursing, 23(15-16), 2223-2232. https://doi.org/10.1111/jocn.12500

Hone, K. S., \& El Said, G. R. (2016). Exploring the factors affecting MOOC retention: A survey study. Computers \& Education, 98, 157-168. https://doi.org/10.1016/j.compedu.2016.03.016

Jordan, K. (2014). Initial trends in enrolment and completion of massive open online courses. International Review of Research in Open and Distributed Learning, 15(1), 27. https://doi.org/10.19173/irrodl.v15i1.1651

King, C., Kelder, J.-A., Doherty, K., Phillips, R., McInerney, F., Walls, J., Robinson, A., \& Vickers, J. (2014). Designing for quality: The Understanding Dementia MOOC. The Electronic Journal of e-Learning 12(2), 161-171. https://files.eric.ed.gov/fulltext/EJ1034373.pdf

Kizilcec, R. F., Saltarelli, A. J., Reich, J., \& Cohen, G. L. (2017). Closing global achievement gaps in MOOCs. Science, 355(6322), 251-252. https://doi.org/10.1126/science.aag2063

Lee, S. E., Lee, H. Y., \& Diwan, S. (2010). What do Korean American immigrants know about Alzheimer's disease (AD)? The impact of acculturation and exposure to the disease on $\mathrm{AD}$ 
knowledge. International Journal of Geriatric Psychiatry, 25(1), 66-73.

https://doi.org/10.1002/gps.2299

Liyanagunawardena, T., \& Williams, S. (2014). Massive open online courses on health and medicine: Review. Journal of Medical Internet Research, 16(8), e191.

https://doi.org/10.2196/jmir.3439

Liyanagunawardena, T., Williams, S., \& Adams, A. (2013). The impact and reach of MOOCs: A developing countries' perspecitve. eLearning Papers, 33, 1-8.

Loi, S. M., \& Lautenschlager, N. T. (2015). Dementia literacy in older adults. Asia-Pacific Psychiatry, $7(3)$, 292-297. https://doi.org/10.1111/appy.12153

Low, L. F., Anstey, K., Lackersteen, S. M., Camit, M., Harrison, F., Draper, B., \& Brodaty, H. (2010). Recognition attitudes and causal beliefs regarding dementia in Italian, Greek and Chinese Australians. Dementia and Geriatric Cognitive Disorders, 30(6), 499-508. $\underline{10.1159 / 000321667}$

Ludecke, D., von dem Knesebeck, O., \& Kofahl, C. (2016). Public knowledge about dementia in Germany-Results of a population survey. International Journal of Public Health, 61(1), 916. https://doi.org/10.1007//s00038-015-0703-X

Mavromaras, K., Knight, G., Isherwood, L., Crettenden, A., Flavel, J., Karmel, T., Moskos, M., Smith, L., Walton, H., \& Wei, Z. (2017). The aged care workforce, 2016.

https://agedcare.royalcommission.gov.au/system/files/2020-06/CTH.0001.1001.2805.pdf

McParland, P., Devine, P., Innes, A., \& Gayle, V. (2012). Dementia knowledge and attitudes of the general public in Northern Ireland: An analysis of national survey data. International Psychogeriatrics, 24(10), 1600-1613. doi:10.1017/S1041610212000658

Prince, M., Wimo, A., Guerchet, M., Ali, G.-C., Wu, Y.-T., \& Prina, M. (2015). World Alzheimer report 2015: The global impact of dementia (An analysis of prevalence, incidence, cost and trends). Alzheimer's Disease International. https://www.alz.co.uk/research/WorldAlzheimerReport2015.pdf

Rambe, P., \& Moeti, M. (2017). Disrupting and democratising higher education provision or entrenching academic elitism: Towards a model of MOOCs adoption at African universities. Educational Technology Research and Development, 65(3), 631-650. https://doi.org/10.1007/s11423-016-9500-3

Roberts, J. S., McLaughlin, S. J., \& Connell, C. M. (2014). Public beliefs and knowledge about risk and protective factors for Alzheimer's disease. Alzheimer's \& Dementia, 10, S381-S389. https://doi.org/10.1016/j.jalz.2013.07.001

Robinson, A., Eccleston, C., Annear, M., Elliott, K.-E., Andrews, S., Stirling, C., Ashby, M., Donohue, C., Banks, S., Toye, C., \& McInerney, F. (2014). Who knows, who cares? Dementia knowledge among nurses, care workers, and family members of people living with dementia. Journal of Palliative Care, 3o(3), 158-165. https://doi.org/10.1177/082585971403000305 
Small, J., Chan, S. M., Drance, E., Globerman, J., Hulko, W., O’Connor, D., Perry, J., Stern, L., \& Ho,

L. (2015). Verbal and nonverbal indicators of quality of communication between care staff and residents in ethnoculturally and linguistically diverse long-term care settings. Journal of Cross-Cultural Gerontology, 3o(3), 285-304. https://doi.org/10.1007/s10823-015-9269-6

Smith, B. J., Ali, S., \& Quach, H. (2014). Public knowledge and beliefs about dementia risk reduction: A national survey of Australians. BMC Public Health, 14(1), 661.

https://doi.org/10.1186/1471-2458-14-661

United National Educational, Science and Cultural Organization. (2008). Mother tongue matters: Local language as a key to effective learning. https://unesdoc.unesco.org/ark:/48223/pfoooo161121

Web Accessibility Initiative. (2019). Introduction to Web accessibility. https://www.w3.org/WAI/fundamentals/accessibility-intro/

Walsh, K., \& Shutes, I. (2013). Care relationships, quality of care and migrant workers caring for older people. Ageing and Society, 33(3), 393-420. https://doi.org/10.1017/S0144686X11001309

World Health Organization. (2015). Dementia: A public health priority. World Health Organizaton. https://www.who.int/mental health/neurology/dementia/dementia thematicbrief executiv esummary.pdf?ua $=1$

\section{Athabasca \\ University}

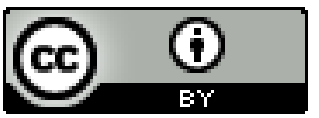

